\title{
A reestruturação curricular de uma rede municipal de ensino, numa perspectiva colaborativa
}

\author{
The curricular restructuring of a municipal education system, \\ in a collaborative perspective
}

SARMENTO, Dirléia Fanfa ${ }^{1}$, MENEGAT, Jardelino ${ }^{2}$, RAMOS, Roberto Carlos ${ }^{3}$

\begin{abstract}
RESUMO
$\mathrm{O}$ artigo focaliza a reestruturação curricular de uma rede municipal de ensino. Decorre de uma pesquisaação relativa à implantação da BNCC. Protagonizaram o estudo professores de 17 escolas desta rede. Foram priorizados no processo o diálogo, o comprometimento político com a mudança da realidade educacional e a democracia. A análise documental, a observação e os registros no Diário de Campo indicam: a) certa resistência à participação, b) concepção de currículo com foco nos conteúdos, c) visão burocrática sobre o planejamento curricular, e d) ceticismo em relação à BNCC.
\end{abstract}

Palavras-chave: Currículo; Educação Infantil; Ensino Fundamental; BNCC.

\begin{abstract}
The article focuses on the curricular restructuring of a municipal school system. It results from an action research related to the implantation of the BNCC. Teachers from 17 schools in this system led the study. Dialogue, political commitment to changing educational reality and democracy were prioritized in the process. The documentary analysis, observation and records in the Diário de Campo indicate: a) some resistance to participation, b) curriculum design with a focus on content, c) bureaucratic view on curriculum planning, and d) skepticism about the BNCC.
\end{abstract}

Keywords: Curriculum; Child education; Elementary School; BNCC.

\section{INTRODUÇÃO}

De acordo com a legislação educacional (BRASIL, 1996; BRASIL, 2009; BRASIL, 2010; BRASIL, 2017) o currículo escolar está constituído por uma base comum e uma parte diversificada. As orientações relativas à base comum estão previstas no

\footnotetext{
${ }^{1}$ Professora permanente do Programa de Pós-Graduação em Educação da Universidade La Salle (Canoas/RS). E-mail: dirleia.sarmento@unilasalle.edu.br.

${ }^{2}$ Professor permanente do Programa de Pós-Graduação em Educação da Universidade Católica de Petrópolis (Petrópolis/RJ).

${ }^{3}$ Professor convidado do Programa de Pós-Graduação em Gestão e Administração Educacional (Lichinga/Moçambique).
} 
documento da BNCC, sendo que esta base "deve ser complementada, em cada sistema de ensino e em cada estabelecimento escolar, por uma parte diversificada, exigida pelas características regionais e locais da sociedade, da cultura, da economia e dos educandos" (BRASIL, 1996, artigo 26).

Articulada a BNCC, no Estado do Rio Grande do Sul é obrigatória a observação do que propõe o Referencial Curricular Gaúcho (RIO GRANDE DO SUL, 2018). Na BNCC (BRASIL, 2017), a organização do currículo tem como foco o desenvolvimento de competências. Dessa forma,

\begin{abstract}
Por meio da indicação clara do que os alunos devem "saber" (considerando a constituição de conhecimentos, habilidades, atitudes e valores) e, sobretudo, do que devem "saber fazer" (considerando a mobilização desses conhecimentos, habilidades, atitudes e valores para resolver demandas complexas da vida cotidiana, do pleno exercício da cidadania e do mundo do trabalho), a explicitação das competências oferece referências para o fortalecimento de ações que assegurem as aprendizagens essenciais definidas na BNCC. (BRASIL, 2017, p. 14, grifo do documento).
\end{abstract}

Com a promulgação da Base Nacional Comum Curricular (BRASIL, 2017) e a obrigatoriedade de sua implantação, até o ano de 2020, os sistemas e as redes de ensino (e respectivas escolas) do território nacional tiveram de reorganizar os currículos escolares, contemplando o proposto neste documento. Autoras tais como Lopes (2018) e Macedo (2018) criticam a tentativa de centralidade e homogeneidade do currículo, via BNCC. Para Lopes (2018, p. 25-26):

Por maior que seja o detalhamento curricular, ele sempre é interpretado de diferentes maneiras nas escolas: não há como conter esse processo, porque tal processo é próprio da linguagem, da comunicação, educacional ou não, da leitura de qualquer texto. Uma base curricular, por mais detalhada e explícita que seja, será lida contextualmente de formas diferentes. Professores e professoras com formações diferentes, escolas com diferentes condições de trabalho, histórias de vida diferentes dos alunos e alunas, docentes com salários e comprometimentos distintos com a prática educacional, interesses diferentes e, sobretudo, relações dinâmicas entre sujeitos e contextos farão com que o currículo seja interpretado de forma diferente.

O currículo, enquanto um campo de estudos específico, é um "espaço em que diferentes atores sociais, detentores de determinados capitais sociais e culturais na área, legitimam determinadas concepções sobre a teoria do currículo e disputam entre si o poder de definir quem tem a autoridade na área” (LOPES; MACEDO, 2010, p. 17-18). Conforme assevera Sacristán (2013, p. 20): 
Uma vez que admitimos que o currículo é uma construção onde se encontram diferentes respostas a opções possíveis, onde é preciso decidir entre as possibilidades que nos são apresentadas, esse currículo real é uma possibilidade entre outras alternativas. [...] Não é algo neutro, universal e imóvel, mas um território controverso e mesmo conflituoso a respeito do qual se tomam decisões, são feitas opções e se age de acordo com orientações que não são as únicas possíveis. Definir quais as decisões tomar, após avaliá-las, não é um problema técnico (ou melhor, não é fundamentalmente uma tarefa técnica, pois as decisões tomadas afetam sujeitos com direitos, implicam explícita ou implicitamente opções a respeito de interesses e modelos de sociedades, avaliações do conhecimento e a divisão de responsabilidades.

Ao se reestruturar o currículo, dispositivos tais como a Proposta Educativa e os Planos de Estudo também tiveram de ser revisitados. Isso porque, o currículo, traduzido nos Planos de Estudos, explicita os fundamentos e os pressupostos que norteiam o ideário educativo de um sistema, de uma rede e de uma escola. Portanto, a concepção curricular precisa estar em consonância com este ideário educativo.

Tendo presente o exposto, o artigo apresenta reflexões sobre o processo de reestruturação curricular de uma rede municipal de ensino, de uma cidade situada na Região Metropolitana de Porto Alegre. O processo foi coordenado pela equipe de gestão pedagógica da Secretaria Municipal de Educação e Cultura de Nova Santa Rita/RS (SMEC) e conduzido pela pesquisadora de uma Universidade por meio de uma pesquisaação, com o auxílio de dois pesquisadores colaboradores.

Inspirados na experiência de Freire como Secretário de Educação em São Paulo (entre os anos de 1989 e 1991), foram priorizados nessa trajetória constitutiva o diálogo, o comprometimento político com a mudança da realidade educacional e a democracia, considerando-os pressupostos essenciais nesse processo (FREIRE, 2006). Igualmente, são contemplados os pressupostos de autores que apresentam reflexões acerca do currículo (SACRISTÁN, 2013; LOPES; MACEDO, 2010; LOPES, 2018); da gestão em rede (LÜCK, 2000) e do desenvolvimento de competências (ZABALA; ARNAU, 2010).

Vale ressaltar que à época de Freire ainda não havia documentos de cunho obrigatório relativos à base comum do currículo. Em 1997, os Parâmetros Curriculares Nacionais (Brasil, 1997) foram uma tentativa de introduzir as competências como mote orientador do currículo e da ação educativa.

Entretanto, apesar de com a BNCC (BRASIL, 2017) se evidenciar as competências, as reflexões de Freire acerca dos conteúdos programáticos e da "concepção bancária da educação" (FREIRE, 1987), são de extrema relevância e atualidade. O desenvolvimento de competências não exclui os conteúdos. Pelo contrário, requer o 
ensino e a aprendizagem de conteúdos (o que é necessário saber, os conteúdos conceituais) articulados às habilidades (o que se deve saber fazer, os conteúdos procedimentais) e às atitudes (de que forma se deve ser, os conteúdos atitudinais) (ZABALA; ARNAU, 2010) sendo que estes últimos explicitam um conjunto de valores. Tais observações são necessárias para salvaguardar-se os pressupostos freirianos, preservando suas especificidades contextuais e conceituais, gestadas num momento histórico-social, político e econômico distinto do atual. Nas palavras de Freire (1967, p. 35):

Não há educação fora das sociedades humanas e não há homem no vazio. $\mathrm{O}$ esforço educativo que desenvolveu o Autor [...] ainda que tenha validade em outros espaços e em outro tempo, foi todo marcado pelas condições especiais da sociedade brasileira. Sociedade intensamente cambiante e dramaticamente contraditória. Sociedade em "partejamento", que apresentava violentos embates entre um tempo que se esvaziava, com seus valores, com suas peculiares formas de ser, e que "pretendia" preservar-se e um outro que estava por vir, buscando configurar-se. (grifo do autor).

Em termos de estrutura, o texto inicia situando a temática abordada e explicitando alguns pressupostos teóricos balizadores do estudo. A seguir, o contexto do estudo é descrito, caracterizando a abordagem e os procedimentos metodológicos adotados. $\mathrm{Na}$ sequência, o processo de reorganização curricular é apresentando, havendo um diálogo reflexivo com os autores que embasam a fundamentação teórica do estudo realizado.

\section{CONTEXTO DO ESTUDO}

A pesquisa-ação, financiada pelo Conselho Nacional de Desenvolvimento Científico e Tecnológico (CNPq), teve como problemática norteadora as perspectivas e os desafios da implantação da BNCC, enquanto uma política pública articulada ao ideário do direito à educação de qualidade, para a ação educativa na rede municipal de ensino.

A pesquisa-ação requer a reflexão sobre a relação entre teoria e prática. Tal abordagem "articula a relação entre teoria e prática no processo mesmo de construção do conhecimento [...] a própria investigação se converteria em ação, em intervenção social, possibilitando ao pesquisador a atuação efetiva sobre a realidade estudada" (MIRANDA; RESENDE, 2006, p. 514). Conforme esclarece Carr (1996, p. 15), “o fato de teorizar forma parte do processo dialético de autotransformação e de mudança social: o processo através do qual os indivíduos reconstroem a si mesmos e, ao mesmo tempo, reconstroem sua vida social". 
O ideário do direito à educação de qualidade tem feito parte da agenda educacional, com mais ênfase, desde a década de 90. Dispositivos internacionais tais como a Declaração Mundial sobre Educação para Todos: satisfação das necessidades básicas de aprendizagem (UNESCO, 1990); a Declaração de Dakar - Educação para todos: cumprindo nossos compromissos coletivos (UNESCO, CONSED, AÇÃO EDUCATIVA, 2001); a Declaração de Incheon e Marco de Ação (UNESCO, 2016) tem sido os principais mobilizadores dessa discussão, influenciando as políticas públicas educacionais de vários países.

Conforme Akkari (2017, p. 941): "De modo geral, para todos os países, uma agenda internacional apoiada pela Organização das Nações Unidas tem um forte valor simbólico". No caso do Brasil, o propostos nas Declarações mencionadas, é perceptível na Lei de Diretrizes e Bases da Educação Nacional (BRASIL, 1996); nas Diretrizes Curriculares Nacionais para a Educação Infantil (BRASIL, 2009); nas Diretrizes Curriculares Gerais para a Educação Básica (BRASIL, 2010a); nas Diretrizes Curriculares Nacionais para o Ensino Fundamental de 9 (nove) anos (BRASIL, 2010b); nas Diretrizes Curriculares Gerais para a Educação Básica (BRASIL, 2013); no Plano Nacional de Educação 2014-2024 (BRASIL, 2014); e na Base Nacional Comum Curricular (BRASIL, 2017), dentre outros. No entender de Freire (1992, p. 23)

[...] educação e qualidade são sempre uma questão política, fora de cuja reflexão, de cuja compreensão não nos é possível entender nem uma nem outra. Não há, finalmente, educação neutra nem qualidade por que lutar no sentido de reorientar a educação que não implique uma opção política e não demande uma decisão, também política de materializá-la.

Nessa perspectiva, prima-se por uma educação de qualidade social. Segundo o Informe Mesa Redonda de Ministros sobre la Calidad de la Educación (UNESCO, 2003, p.32):

A abordagem da UNESCO é promover a educação de qualidade como parte dos direitos humanos, e defender uma abordagem baseada em direitos por meio de processos educacionais. Podemos pensar nisso como o direito de acessar a educação, o exercício dos direitos na educação e o gozo de outros direitos graças à educação. Isso implica, por exemplo, uma mudança fundamental nas estruturas de ensino e nas práticas pedagógicas, no gerenciamento de sistemas educacionais, no conteúdo e uso de materiais didáticos, no treinamento de professores, no intercâmbio de informações e experiências, e exige a participação de todas as partes interessadas em todos os aspectos da educação e da aprendizagem. (tradução nossa).

Fundamentada na ideia de movimento espiralado (LEWIN, 2006) ou dos movimentos espirais cíclicos, os quais viabilizam e implicam no "efeito recursivo em 
função de uma reflexão permanente sobre a ação" (BARBIER, 2002, p. 11) a pesquisa foi realizada em três fases articuladas. Na primeira, no ano de 2018, ocorreu a revitalização da Proposta Educativa da Secretaria Municipal de Educação e Cultura (SMEC). Na segunda, a revitalização das Propostas Educativas (ou Projeto PolíticoPedagógico) de cada uma das 17 escolas pertencentes à rede municipal. Na terceira, foco deste artigo, a revitalização curricular e sua tradução nos Planos de Estudos da Educação Infantil e do Ensino Fundamental, no âmbito da rede de ensino. Ambas as fases realizadas entre os anos de 2018 e 2019. Segundo Barbier (2007, p. 14),

A pesquisa-ação obriga o pesquisador de implicar-se. Ele percebe como está implicado pela estrutura social na qual ele está inserido e pelo jogo de desejos e de interesses de outros. Ele também implica os outros por meio do seu olhar e de sua ação singular no mundo. [...] O pesquisador descobre que na pesquisa-ação [...] não se trabalha sobre os outros, mas e sempre com a outros. (grifo do autor).

Dessa forma, a ação-intervenção tanto do pesquisador quanto o protagonismo dos atores são centrais nessa modalidade investigativa. Conforme salienta Barbier (2002, p. 70), "Não há pesquisa ação sem participação coletiva". Portanto, protagonizaram o processo de revitalização, 26 professores (8 da Educação Infantil e 18 do Ensino Fundamental). Os dados foram coletados por meio da análise documental (SÁ-SILVA, ALMEIDA, GUINDANI, 2009), da observação (MOROZ; GIANFALDONI, 2006; VIANNA, 2007) e dos registros no Diário de Campo (BAUER; GASKELL, 2003) relativos aos encontros realizados com cada Grupo de Trabalho.

\section{O PROCESSO DE REESTRUTURAÇÃO CURRICULAR}

A abordagem do processo de reestruturação curricular na rede de ensino que foi realizado estudo requer que seja retomado, anteriormente, a concepção que se tem sobre a gestão da e com a rede de ensino. De acordo com Lück (2000, p.20), "A ideia de rede tem como pano de fundo a compreensão da realidade como um sistema". Conforme a autora, neste sistema "todos os elementos estão interligados, de maneira que o que acontece em um elemento do sistema, afeta a todos os demais elementos que o compõem" (LÜCK, 2000, p.20). Continua a autora explicando que:

Não basta, no entanto, o estabelecimento de objetivos e propósitos comuns, para se construir a rede. Torna-se necessário que se dedique continuamente e com atenção especial, ao seu funcionamento. A rede só existe pela ação constante de comunicação, associação, intercâmbio e reforço recíproco que fazem entre si as partes componentes das redes, no sentido de sustentar, alimentar e promover o seu ideário comum. (LÜCK, 2000, p.21). 
Diante do exposto, a Secretaria de Educação possui um papel central, pois é de competência deste órgão público a gestão educacional de uma rede de ensino. O dirigente deste órgão possui a responsabilidade de assegurar que a legislação vigente seja observada e, nesse contexto, que o princípio constitucional da gestão democrática (BRASIL, 1988) se efetive. Também é deste órgão que são emanadas as diretrizes educacionais que conferem identidade e unidade à rede de ensino.

Apesar de passados 30 anos, os desafios enfrentados por Freire na Secretaria de Educação de São Paulo, relatados no livro A Educação na Cidade, ainda hoje são perseguidos na gestão educacional. No prefácio dessa obra, Moacir Gadotti e Carlos Alberto Torres, sintetizam os "quatro objetivos que marcam a ação da administração Freire em São Paulo", a saber:

1) Ampliar o acesso e a permanência dos setores populares - virtuais únicos usuários da educação pública; 2) democratizar o poder pedagógico e educativo para que todos alunos, funcionários, professores, técnicos educativos, pais de família, se vinculem num planejamento autogestionado, aceitando as tensões e contradições sempre presentes em todo esforço participativo, porém buscando uma substantividade democrática; 3 ) incrementar a qualidade da educação, mediante a construção coletiva de um currículo interdisciplinar e a formação permanente do pessoal docente; 4) finalmente, o quarto grande objetivo da gestão não poderia ser de outra maneira - é contribuir para eliminar o analfabetismo de jovens e adultos em São Paulo.

Acesso e permanência, gestão democrática e participação, qualidade da educação, formação docente e eliminação do analfabetismo de jovens e adultos são temas constantes na agenda educacional, implicando conforme já exposto, nas políticas públicas educativas dos países. De certa forma, isso demonstra a atualidade dos pressupostos freirianos e o quão visionário ele foi ao defender um "modelo político-pedagógico" que contemplasse as classes populares. Nas palavras de Freire (2006, p. 28):

A natureza da prática educativa, a sua necessária diretividade, os objetivos, os sonhos que se perseguem na prática não permitem que ela seja neutra, mas política sempre. É a isso que eu chamo de politicidade da educação, isto é, a qualidade da educação de ser política. A questão que se coloca é saber que política é essa, a favor de quê e de quem, contra o quê e contra quem se realiza.

No entender de Freire (2006, p. 41), "Não há administração ou projetos pedagógicos neutros" (FREIRE, 2006, p. 41). Portanto, "Ninguém democratiza a escola sozinho, a partir do gabinete do secretário" (FREIRE, 2006, p. 43). Desse ponto de vista, 
um projeto educativo de rede e suas traduções nos dispositivos orientadores da ação educativa requer uma construção coletiva com aqueles que compõem esta rede, conferindo-lhe uma identidade.

Um dos desafios assumidos por Freire em sua gestão foi a reformulação do currículo. Tarefa esta que, segundo ele, foi delegada à professora Ana Maria Saul, da PUCrs (Pontifícia Universidade Católica), sendo a referida professora considerada por Freire "uma das mais competentes especialistas brasileiras em Teoria do Currículo". (FREIRE, 2006, p. 24). Assim, a relação e o diálogo entre a Universidade e a Educação Básica, enfatizada na atualidade (LUDKE; CRUZ, 2005) já era exercitada por Freire na sua atuação gestora. Na compreensão de Freire (2006, p. 81-82):

[...] a universidade tem uma responsabilidade social a cumprir junto aos demais graus de ensino e uma contribuição fundamental a dar no que diz respeito à compreensão do conhecimento, às perspectivas de avanço nas diferentes dimensões do conhecimento bem como nas questões de formação dos profissionais que atuam nas redes de ensino. Considero também que a aproximação da universidade com a escola permite que a própria universidade se aproprie de um conhecimento da realidade que a fará repensar seu ensino e a sua pesquisa.

Diante do exposto, na relação entre Universidade e Educação Básica acontece o processo de retroalimentação da articulação entre teoria e prática, contribuindo para a qualificação das práticas educativas em ambos os níveis de ensino e da formação dos futuros professores. Ao se referir a reformulação curricular empreendida no decorrer de sua gestão, com a contribuição da Universidade, Freire (2006, p. 24) enfatiza que:

Evidentemente, para nós, a reformulação do currículo não pode ser algo feito, elaborado, pensado por uma dúzia de iluminados cujos resultados finais são encaminhados em forma de "pacotes" para serem executados de acordo ainda com as instruções e guias igualmente elaborados pelos iluminados. A reformulação do currículo é sempre um processo político-pedagógico e, para nós, substantivamente democrático. (FREIRE, 2006, p.24, grifo do autor).

Dessa forma, qualquer iniciativa relativa a (re)construção de fundamentos ou de dispositivos orientadores da ação educativa de uma rede de ensino requer o diálogo, o comprometimento político com a mudança da realidade educacional e a democracia.

Conforme exposto, apesar do ideário do desenvolvimento de competências estar presente desde a década de noventa em dispositivos tais como os Parâmetros Curriculares Nacionais (BRASIL, 1997), somente com a BNCC ele se torna obrigatório. Há de se considerar que a mudança na concepção curricular requer que sejam repensados os processos de ensino, de aprendizagem e de avaliação. O ambiente escolar, compreendido 
sobre a perspectiva da articulação entre o espaço físico-material e as relações que nele se estabelecem, também explicita a concepção curricular.

Freire (2006, p. 33), insiste que é necessário transformar as escolas em "centros de criatividade, em que se ensine e se aprenda com alegria". Mas, para que isso se concretize, é preciso assegurar "condições materiais condignas- salários decentes, as escolas conservadas e reparadas em tempo, agilização das medidas burocráticas indispensáveis ao bom funcionamento. Respeito aos educadores, aos educandos, a todos". (FREIRE, 2006, p. 33). Continua explicando:

Sonhamos com uma escola que, porque séria, se dedique ao ensino de forma competente, mas, dedicada, séria e competentemente ao ensino, seja uma escola geradora de alegria. O que há de sério, até de penoso, de trabalhoso, nos processos de ensinar, de aprender, de conhecer não transforma este quefazer em algo triste. Pelo contrário, a alegria de ensinar-aprender deve acompanhar professores e alunos em suas buscas constantes. (FREIRE, 2006, p. 37).

Contudo, mesmo acreditando nesse "sonho pedagógico", Freire (2006, p. 44) é enfático ao afirmar que "Não há para nós forma mais adequada e efetiva de conduzir o nosso projeto de educação do que a democrática, do que o diálogo aberto, corajoso".

Durante o ano de 2019, a equipe de gestão pedagógica da Secretaria Municipal de Educação e Cultura (SMEC) priorizou nos encontros formativos direcionados aos docentes o estudo da BNCC e demais dispositivos. Para Freire (1992, p. 37), "A melhora da qualidade da educação implica a formação permanente dos educadores. E a formação permanente se funda na prática de analisar a prática". Dessa forma, "É pensando sua prática, naturalmente com a presença de pessoal altamente qualificado, que é possível perceber embutida na prática uma teoria não percebida ainda, pouco percebida ou já percebida, mas pouco assumida" (Ibidem). Nessa perspectiva, retoma-se a relevância da relação entre a Universidade e a Educação Básica.

Como parte do processo da pesquisa-ação, os encontros formativos foram conduzidos por uma das pesquisadoras. Tais encontros tiveram como objetivo mobilizar os profissionais da educação sobre a importância da BNCC, analisando suas decorrências para a revitalização dos dispositivos atinentes à organização e ao planejamento da ação educativa no município. Conforme Barbier (2007, p. 19), “a pesquisa-ação é eminentemente pedagógica e política. [...] Ela pertence por excelência à categoria da formação, quer dizer, a um processo de criação e formas simbólicas interiorizadas, estimulado pelo sentido do desenvolvimento do potencial humano". 
No decorrer dos encontros formativos, além da análise e discussão da BNCC, foi abordado o Referencial Curricular Gaúcho e retomadas as Diretrizes Curriculares da Educação Infantil (BRASIL, 2009) e do Ensino Fundamental (BRASIL, 2010a). A retomada das Diretrizes Curriculares (BRASIL, 2009, 2010) foi necessária para salientar a parte diversificada do currículo e que a proposição da mesma é de competência de cada sistema, rede de ensino e escola, salvaguardando-se as identidades, as características e especificidades das propostas e contextos educativos. Também foram revisitados os Planos de Estudos vigentes na rede.

A partir do trabalho realizado, teve início a elaboração dos documentos relativos a base comum do currículo (um da Educação Infantil e o outro do Ensino Fundamental), de forma a contemplar o proposto pela BNCC e o Referencial Curricular Gaúcho. Nessa parte, conforme exposto, efetivou-se a terceira fase da pesquisa, foco deste artigo.

Devido à complexidade de tal ação e, considerando que ainda seria necessário planejar a parte diversificada do currículo, contemplando as características e especificidades da rede de ensino (e posteriormente, complementada a parte especifica de cada contexto escolar) os professores foram convidados a participar de Grupos de Trabalho (GT). Foi acordado com a SMEC que os grupos formados por professores representantes de cada escola, participariam das reuniões do GT no seu respectivo horário de trabalho, sendo responsabilidade da escola auxiliar na substituição desses profissionais.

Do conjunto total de 368 professores (Educação Infantil e Ensino Fundamental) e 69 assistentes (Educação Infantil), 26 professores se dispuseram a participar desta ação. Desse conjunto, 8 eram da Educação Infantil (creche e pré-escola), 9 dos anos iniciais e 9 professores dos anos finais (3 de Matemática, 2 de Língua Inglesa, 1 de Arte, 1 de Educação Física, 1 de História e 1 de Ensino Religioso). Os demais componentes (Língua Portuguesa, Geografia e Ciências) não tiveram representatividade, sendo realizado um trabalho posterior. Da mesma forma, nem todas as escolas tiveram profissionais representando-as. A revitalização do currículo, assim como a prática educativa é um ato político, pois:

Tem que ver com: que conteúdos ensinar, a quem, a favor de quê, de quem, contra quê, contra quem, como ensinar. Tem que ver com quem decide sobre que conteúdos ensinar, que participação têm os estudantes, os pais, os professores, os movimentos populares na discussão em torno da organização dos conteúdos programáticos. (FREIRE, 2006, p. 45). 
Desse ponto de vista, chama a atenção o fato dos componentes curriculares citados não terem uma representatividade docente, mesmo sendo oportunizadas condições consideradas favoráveis à tal participação. Talvez aqui resida uma das lacunas do estudo, pois os fatores que interfeririam na ausência de adesão ou no número reduzido de professores participantes por componente curricular (a proposta inicial seria pelo menos três para cada componente) não foram investigados. Possivelmente, a realização deste estudo poderia contribuir para a identificação dos aspetos que (des) mobilizam a participação e o engajamento docente num projeto coletivo.

O currículo é o cerne do itinerário formativo, sendo ele a bússola que orienta a ação educativa. Parece que, se o professor não se apropria do currículo desde a sua proposição é bem provável que sua ação educativa não ocorra de forma engajada e comprometida, tornando-se um ato mecânico. No entender de Freire (1992, p. 36), a neutralidade em educação é impossível, pois

É o uso da liberdade que nos leva à necessidade de optar e esta à
impossibilidade de ser neutros. Agora bem, a impossibilidade total de
ser neutros em face do mundo, do futuro [...] nos coloca
necessariamente o direito e o dever de nos posicionar como educadores.
O dever de não nos omitir. O direito e o dever de viver a prática
educativa em coerência com a nossa opção política.

Conforme Freire (2006, p. 58), “A gente se faz educador, a gente se forma, como educador, permanentemente, na prática e na reflexão sobre a prática”. O fato da BNCC e do Referencial Curricular Gaúcho (no caso do Rio Grande do Sul) serem de cunho obrigatório, por si só já deveria ser um aspecto para os docentes se sentirem mobilizados ao aprofundamento, à reflexão e à discussão. Nesse entendimento, a participação dos professores nessa construção coletiva foi um espaço de suma importância para que cada um pudesse "dizer a sua palavra" (FREIRE, 1987). Assim,

Se é dizendo a palavra com que, "pronunciando" o mundo, os homens o transformam, o diálogo se impõe como caminho pelo qual os homens ganham significação enquanto homens. Por isto, o diálogo é uma exigência existencial. $\mathrm{E}$, se ele é o encontro em que se solidariza o refletir e o agir de seus sujeitos endereçados ao mundo a ser transformado e humanizado, não pode reduzir-se a um ato de depositar ideias de um sujeito no outro, nem tampouco tornar-se simples troca de ideias a serem consumidas pelos pemutantes. (FREIRE, 1987, p. 51, grifo do autor).

Com base no exposto, "o diálogo começa na busca do conteúdo programático" (FREIRE, 1987, p. 53). Freire (1987, p. 53-54) reflete que: 
Para o educador-educando, dialógico, problematizador, o conteúdo programático da educação não é uma doação ou uma imposição - um conjunto de informes a ser depositado nos educandos, mas a revolução organizada, sistematizada e acrescentada ao povo, daqueles elementos que este lhe entregou de forma desestruturada.

Considerando-se as especificidades curriculares e também, de cada etapa, os professores foram organizados em três grupos: a) GT1, composto pelos professores da Educação Infantil, b) GT2 pelos professores dos anos iniciais do Ensino Fundamental e, c) GT3 pelos professores dos anos finais do Ensino Fundamental. Assim, neste mesmo ano de 2019, além das formações sobre a BNCC, foram realizados 6 encontros com cada GT, com 4 horas cada. No intervalo entre os encontros, os integrantes de cada GT eram incentivados a partilhar com seus pares as reflexões realizadas, especialmente aqueles professores que ficaram sozinhos nos componentes curriculares. Para estes, durantes os encontros, o diálogo somente foi possível com os colegas de outros componentes da mesma área. Contudo, nessa etapa inicial, o diálogo entre pares sobre o mesmo componente ficou comprometido. Retoma-se a premissa de Freire (1987, p.104) quando ele assevera que:

A colaboração, como característica da ação dialógica, que não pode darse a não ser entre sujeitos, ainda que tenham níveis distintos de função, portanto, de responsabilidade, somente pode realizar-se na comunicação. O diálogo, que é sempre comunicação, funda a colaboração.

Ao revisitar os registros das observações dos encontros no Diário de Campo da pesquisadora, algumas falas e posturas dos docentes durante o processo geraram debates no grupo. Dentre estas destacam-se: “o papel aceita tudo [...] esse planejamento é só uma questão burocrática [...] depois cada um faz o que quer na sua sala de aula" (D1); "na teoria tudo é muito bonito [...] na prática é outra coisa" (D7); "aqui na BNCC diz que temos de trabalhar esses conteúdos [...] mas na época que fiz a graduação não aprendemos isso" (D24); “o que adianta colocar no planejamento se na escola não vamos ter materiais para poder ensinar” (D21); “é muita coisa para ser trabalhada com só dois períodos por semana [...] e ainda tem a parte específica do município e da escola" (D17). Cada uma dessas falas possui conteúdos que apontam para concepções que mereceriam ser aprofundadas, considerando-se que parecem já fazer parte do senso comum no magistério. De modo geral, denotam o distanciamento entre a teoria e a prática; o planejamento curricular e a sua tradução em documentos como um ato burocrático; a ação educativa enquanto uma iniciativa individual, desvinculada de um ideário coletivo e a 
responsabilização da formação inicial pelas possíveis lacunas do preparo do futuro professor (como se o professor não tivesse de estar em continua formação no decorrer de sua trajetória).

Outro aspecto observado é que, apesar das formações realizadas, os docentes ainda tinham como centralidade os conteúdos. Isso indica que a perspectiva do currículo para o desenvolvimento de competências precisa ser aprofundado nas formações continuadas para que possa se tornar efetivo no cotidiano escolar. De acordo com Freire (1996, p. 21):

[...] na formação permanente dos professores, o momento fundamental é o da reflexão crítica sobre a prática. É pensando criticamente a prática do eu de ontem que se pode melhorar a próxima prática. O próprio discurso teórico, necessário à reflexão crítica, tem de ser de tal modo concreto que quase se confunda com a prática. O seu "distanciamento" epistemológico da prática enquanto objeto de sua análise, deve dela "aproximá -lo" ao máximo. Quanto melhor faça esta operação tanto mais inteligência ganha da prática em análise e maior comunicabilidade exerce em torno da superação da ingenuidade pela rigorosidade. Por outro lado, quanto mais me assumo como estou sendo e percebo a ou as razões de ser de porque estou sendo assim, mais me torno capaz de mudar, de promover-me, no caso, do estado de curiosidade ingênua para o de curiosidade epistemológica. (grifo do autor).

Oportuno salientar que, mesmo sendo concepções e posturas de um grupo de professores (e portanto, não generalizáveis à categoria docente) ainda assim indicam a necessidade de retomá-las. Dito de outro modo, se tais concepções são constantes entre àqueles que se dispuseram a participar e colaborar numa construção coletiva, o que dizer de outros que optaram por não participar. Com tais observações não se pretende estabelecer juízos valorativos, mas sim enfatizar que a construção e efetivação de um ideário educativo em rede requer concepções e posturas condizentes com tal ideário.

Em novembro de 2019, os GTs concluíram a primeira versão dos documentos relativos à proposta curricular da Educação Infantil e do Ensino Fundamental. Estes documentos foram encaminhados às equipes diretivas de cada escola, para serem analisados em conjunto com o corpo docente e feitas as observações (acréscimos, supressões, solicitação de esclarecimentos) consideradas pertinentes.

Passado o tempo acordado, os documentos com as devidas observações foram reencaminhados à pesquisadora, que juntamente com os pesquisadores colaboradores, procederam às adequações indicadas. Segundo Barbier (2007, p. 18): “O pesquisador desempenha então, seu papel profissional numa dialética que articula constantemente a 
implicação e o distanciamento, a afetividade e a racionalidade, [...], a mediação e o desafio, a autoformação e a heteroformação".

Apesar das contribuições terem sido em número reduzido, a segunda versão dos documentos foi reenviada às equipes diretivas com o objetivo de, no decorrer do ano de 2020, concomitantemente a sua implantação, serem socializados, discutido e aperfeiçoados gradativamente, nas instâncias participativas de cada comunidade educativa. Na gestão democrática, as instâncias de participação (Conselhos Escolares, agremiações estudantis, lideranças de turmas) são de fundamental importância. Entretanto, no conjunto de escolas da rede em estudo, existem escolas que não possuem um Conselho Escolar constituído, e algumas que o possuem, por vezes tais Conselhos não são efetivos em termos de participação.

Devido a Pandemia do COVID-19, o ano de 2020 foi atípico em todos os segmentos sociais, afetando diretamente à educação. Com as medidas de distanciamento social, a estratégia adotada pela rede de ensino priorizou o atendimento dos estudantes, buscando viabilizar a continuidade dos estudos. Outras ações, tais como a prevista em relação à reflexão sobre a estrutura curricular com as instâncias participativas nas escolas foram prorrogadas e estão sendo delineadas estratégias par serem efetivadas no decorrer do ano de 2021.

\section{CONSIDERAÇÕES FINAIS}

O artigo teve como foco a reestruturação curricular de uma rede municipal de ensino, tendo-se presente as demandas oriundas da promulgação da BNCC e a obrigatoriedade de sua implantação no território nacional. Compreendendo a educação como um ato político, na condução do processo de revitalização foram priorizados os pressupostos freirianos relativos à gestão democrática, ao diálogo, ao comprometimento político com a mudança da realidade educacional e a democracia.

Ainda que a etapa de socialização e discussão da proposta curricular com as instâncias participativas na gestão de cada escola será desenvolvida no decorrer do ano de 2021, o estudo viabiliza indicar alguns achados considerados relevantes, tais como: a) certa resistência, por parte dos professores, em participarem do processo de (re)construção curricular, b) a preponderância da concepção de currículo restrita ao desenvolvimento de conteúdos, c) a visão burocrática sobre o planejamento curricular, e d) certo ceticismo em relação à BNCC. 
É por meio da participação, do engajamento e da reflexão coletiva que se torna possível assumir uma posição frente à sociedade e à realidade em que se vive, superando uma visão ingênua e a inexperiência democrática, como aponta Freire (1967). Desse ponto de vista, o diálogo é uma das bases para a (re)construção curricular. O diálogo "nutre-se do amor, da humildade, da esperança, da fé, da confiança" (FREIRE, 1967, p. 107) essenciais em todas as relações humanas.

A BNCC determina um modelo de currículo direcionado ao desenvolvimento de competências. Rompe com a lógica da ênfase na mera listagem de conteúdos, por vezes desprovidos de significados para os estudantes, tão criticada e considerada por Freire como uma educação bancária. De acordo com Freire (2005, p. 45), a opção pelos conteúdos é sempre política, pois "[...] tem que ver com: que conteúdos ensinar, a quem, a favor de quê, de quem, contra quê, contra quem, como ensinar. Tem que ver com quem decide sobre que conteúdos ensinar". Ainda, segundo o autor:

[...] é preciso que a educação esteja - em seu conteúdo, em seus programas e em seus métodos - adaptada ao fim que se persegue: permitir ao homem chegar a ser sujeito, construir-se como pessoa, transformar o mundo, estabelecer com os outros homensrelações de reciprocidade, fazer a cultura e a história. (FREIRE, 1980, p. 39).

Para tanto, é necessário superar a visão de mundo sustentada somente no olhar e na concepção do educador. Segundo Freire (1987, p. 80) "a narração, de que o educador é o sujeito, conduz os educandos à memorização mecânica do conteúdo narrado”. O diálogo é sempre uma necessidade para fazer escolhas. Pensar e propor um currículo que possa contribuir para a emancipação, a autonomia dos educandos e o compromisso com transformação social requer a leitura de mundo, tanto por parte dos educadores quanto dos educandos. Assim, "o diálogo libertador é uma comunicação democrática, que invalida a dominação e reduz a obscuridade, ao afirmar a liberdade dos participantes de refazer sua cultura" (FREIRE; SHOR, 2008, p. 123).

Por fim, qualquer dispositivo que seja de uma abrangência ampla e, ainda mais de cunho obrigatório, tal como a BNCC não está imune a críticas. Tais críticas sempre são importantes e necessárias, pois podem contribuir para a reflexão e possíveis aprimoramentos no documento por ocasião de sua tradução nos currículos das redes de ensino. O currículo não é algo estanque e inacabado. Portanto, requer ser revisitado e discutido continuamente. $\mathrm{O}$ fato de haver críticas não significa desqualificar o processo constitutivo desse documento e, tampouco as contribuições encaminhadas por meio da consulta popular e o empenho de especialistas que a ele se dedicaram. 
Mesmo havendo possíveis limitações, a BNCC efetiva o proposto por ocasião da Lei de Diretrizes e Bases (BRASIL, 1996), no que se refere a base comum do currículo. Da mesma forma, constitui-se numa iniciativa alicerçada na crença e na esperança de ser possível efetivar o direito à educação, minimizando os mecanismos de exclusão que reafirmam as desigualdades sociais e que, por vezes, inviabilizam o acesso, a permanência e ou o êxito no decorrer do itinerário formativo de crianças e adolescentes.

\section{REFERÊNCIAS}

AKKARI, A. A agenda internacional para educação 2030: consenso "frágil” ou instrumento de mobilização dos atores da educação no século XXI? Revista Diálogo Educacional, Curitiba, v. 17, n. 53, p. 937-958. 2017.

BARBIER, R. A pesquisa-ação. Brasília: Plano, 2002.

BARDIN, L. Análise de Conteúdo. São Paulo: Edições 70, 2011.

BAUER, M. W; GASKELL, G. Pesquisa qualitativa com texto, imagem e som: Um manual prático. Petrópolis: Vozes, 2003.

BRASIL. Constituição da República Federativa do Brasil. Brasília, DF: Senado Federal, 1988.

BRASIL. Lei $\mathbf{n}^{0}$ 9.394, de 20 de dezembro de 1996. Estabelece as diretrizes e bases da educação nacional. Diário Oficial da União, Brasília, 23 de dezembro de 1996.

BRASIL. Secretaria de Educação Fundamental. Parâmetros curriculares nacionais: introdução aos parâmetros curriculares nacionais. Brasília: MEC/SEF, 1997.

BRASIL. Ministério da Educação. Conselho Nacional de Educação; Câmara de Educação Básica. Resolução nº 5, de 17 de dezembro de 2009. Fixa as Diretrizes Curriculares Nacionais para a Educação Infantil. Diário Oficial da União, Brasília, 18 de dezembro de 2009, Seção 1, p. 18.

BRASIL. Ministério da Educação. Conselho Nacional de Educação. Parecer CNE/CEB n 7/2010. Diretrizes Curriculares Gerais para a Educação Básica. Brasília, 2010a.

BRASIL. Ministério da Educação. Conselho Nacional de Educação; Câmara de Educação Básica. Resolução no 7, de 14 de dezembro de 2010. Fixa Diretrizes Curriculares Nacionais para o Ensino Fundamental de 9 (nove) anos. Brasília, 2010b.

BRASIL. Ministério da Educação. Secretaria de Educação Básica. Secretaria de Educação Continuada, Alfabetização, Diversidade e Inclusão. Conselho Nacional de Educação. Diretrizes Curriculares Nacionais Gerais para a Educação Básica. Brasília: MEC, SEB, DICEI, 2013. 
BRASIL. Presidência da República. Casa Civil. Subchefia para assuntos jurídicos. Lei $\mathbf{n}^{\circ}$ 13.005, de 25 de junho de 2014. Aprova o Plano Nacional de Educação- PNE e dá outras providências, 2014.

BRASIL. Ministério da Educação. Base Nacional Comum Curricular. Brasília: MEC, 2017.

CARR, Wilfred. Una teoría para la educación: hacia una investigación educativa crítica. Madrid: Morata, 1996.

FREIRE, P. Educação como prática de liberdade. Rio de Janeiro: Paz e Terra, 1967.

FREIRE, P. Conscientização: teoria e prática da libertação - uma introdução ao pensamento de Paulo Freire. 4. ed. São Paulo: Moraes, 1980.

FREIRE, P. Pedagogia do oprimido. 17. ed. Rio de Janeiro: Paz e Terra, 1987.

FREIRE, P. Pedagogia da autonomia: saberes necessários à prática educativa. São Paulo: Paz e Terra, 1996.

FREIRE, P. Política e educação: ensaios. 5. Ed. São Paulo, Cortez, 2001.

FREIRE, P. A Educação na Cidade. 7.ed. São Paulo: Cortez, 2006.

FREIRE, P.; SHOR, I. Medo e ousadia: o cotidiano do professor. 12. ed. Rio de Janeiro: Paz e Terra, 2008.

GADOTTI, M.; TORRES, C. Paulo Freire, Administrador público. FREIRE, P. In: FREIRE, P. A Educação na Cidade. 7.ed. São Paulo: Cortez, 2006. p. 11-17.

LEWIN, K. La investigación-acción y los problemas de las minorías. In: SALAZAR, M. C. (Org.). La investigación - acción participativa. Inicios y desarrollos. Madrid: Editorial Popular - Caracas: Editorial Laboratorio Educativo, 2006. p.15-25.

LOPES, A. C. Apostando na produção contextual do currículo. In: AGUIAR, M. A. da S.; DOURADO, L. F. (Orgs.) A BNCC na contramão do PNE 2014-2024: avaliação e perspectivas. [Livro Eletrônico]. - Recife: ANPAE, 2018. p. 23-27.

LÜCK, H. O desenvolvimento de redes escolares. Revista Gestão em Rede, n. 23, p. 18-21, 2000.

LUDKE, M.; CRUZ, G. B. da. Aproximando universidade e escola de educação básica pela pesquisa. Cadernos de Pesquisa, São Paulo, v. 35, n. 125, p. 81-109, 2005.

MACEDO, E. “A base é a base". E o currículo o que é? In: AGUIAR, Márcia Angela da S. ; DOURADO, Luiz Fernandes (Orgs.). A BNCC na contramão do PNE 20142024: avaliação e perspectivas. [Livro Eletrônico]. - Recife: ANPAE, 2018. p. 28-33.

MIRANDA, M. G. de; RESENDE, A. C. A. Sobre a pesquisa-ação na educação e as armadilhas do praticismo. Revista Brasileira de Educação, v.11, n. 33, p. 511518, 2006. 
MOROZ, M.; GIANFALDONI, M. H. T. A. O Processo de Pesquisa: iniciação Brasília: Liber Livro Editora, $2^{a}$ edição, 2006.

ORGANIZAÇÃO DAS NAÇÕES UNIDAS PARA A EDUCAÇÃO, A CIÊNCIA E A CULTURA (UNESCO). Declaração Mundial sobre Educação para Todos: satisfação das necessidades básicas de aprendizagem. Jomtien, 1990. Disponível em https://unesdoc.unesco.org/ark:/48223/pf0000086291_por. Acesso em 10 fev. 2015.

ORGANIZAÇÃO DAS NAÇÕES UNIDAS PARA A EDUCAÇÃO, A CIÊNCIA E A CULTURA (UNESCO). Educação 2030: Declaração de Incheon e Marco de Ação; rumo a uma educação de qualidade inclusiva e à educação ao longo da vida para todos. Brasília, UNESCO, 2016. Disponível em https://unesdoc.unesco.org/ark:/48223/pf0000243278_por. Acesso 27 agos. de 2017.

ORGANIZAÇÃO DAS NAÇÕES UNIDAS PARA A EDUCAÇÃO, A CIÊNCIA E A CULTURA (UNESCO). CONSED, AÇÃO EDUCATIVA. Educação para Todos: o Compromisso de Dakar. Brasília: Unesco, Consed, Ação Educativa, 2001. Disponível em https://unesdoc.unesco.org/ark:/48223/pf0000127509. Acesso em 6 jan. 2017.

ORGANIZACIÓN DE LAS NACIONES UNIDAS PARA LA EDUCACIÓN, LA CIENCIA Y LA CULTURA (UNESCO). Informe: Mesa Redonda de Ministros sobre la Calidad de la Educación. 32ª reunión de la Conferencia General. Paris, UNESCO, 2003. Disponível em https://unesdoc.unesco.org/ark:/48223/pf0000134972_spa. Acesso 5 dez de 2018.

RIO GRANDE DO SUL. Conselho Estadual de Educação. Resolução no 345, de 12 de dezembro de 2018. Institui e orienta a implementação do Referencial Curricular Gaúcho. Rio Grande do Sul: CEE, 2018.

SÁ-SILVA, J. R.; ALMEIDA, C. D., GUINDANI, J. F. Pesquisa documental: pistas teóricas e metodológicas. Revista Brasileira de História \& Ciências Sociais, n. I, p. 1-15, jul., 2009.

SACRISTÁN, J. G. O que significa o currículo? In: SACRISTÁN, J. G. (Org.). Saberes e incertezas sobre o currículo. Porto Alegre: Penso, 2013. p. 16-35.

VIANNA, H. M. Pesquisa em Educação: a observação. Brasília: Liber Livro Editora, 2007.

ZABALA, A.; ARNAU, L. Como aprender e ensinar competências. Artmed: Porto Alegre, 2010.

Recebido em: 01/10/2021

Aprovado em: 25/10/2021

Publicado em: 27/10/2021 